\title{
Insurance Coverage and Use of Hormones Among Transgender Respondents to a National Survey
}

\author{
Dapbna Stroumsa, $M D, M P H^{1,2}$ \\ Halley P. Crissman, MD, MPH ${ }^{1}$ \\ Vanessa K. Dalton, MD, MPH ${ }^{1-3}$ \\ Giselle Kolenic, $M A^{1}$ \\ Caroline R. Richardson, $M D^{2,4}$ \\ 'Department of Obstetrics and Gyne- \\ cology, University of Michigan, Ann Arbor, \\ Michigan \\ ${ }^{2}$ Institute for Healthcare Policy \& Innova- \\ tion, University of Michigan, Ann Arbor, \\ Michigan \\ ${ }^{3}$ Program on Women's Healthcare Effec- \\ tiveness Research (PWHER), University \\ of Michigan, Ann Arbor, Michigan \\ ${ }^{4}$ Department of Family Medicine, Univer- \\ sity of Michigan Medical School, Ann \\ Arbor, Michigan
}

Conflicts of interest: authors report none.

\section{CORRESPONDING AUTHOR}

Daphna Stroumsa, MD, MPH

Department of Obstetrics and Gynecology

University of Michigan

L4000 Women's Hospital

1500 E Medical Center Dr

Ann Arbor, MI 48109-5276

daphnast@med.umich.edu

\begin{abstract}
PURPOSE We undertook a study to assess the associations between barriers to insurance coverage for gender-affirming hormones (either lack of insurance or claim denial) and patterns of hormone use among transgender adults.

METHODS We used data from the US Transgender Survey, a large national sample of 27,715 transgender adults, collected from August to September 2015. We calculated weighted proportions and performed multivariate logistic regression analyses.
\end{abstract}

RESULTS Of 12,037 transgender adults using hormones, 992 (9.17\%) were using nonprescription hormones. Among insured respondents, 2,528 (20.81\%) reported that their claims were denied. Use of nonprescription hormones was more common among respondents who were uninsured (odds ratio $=2.64 ; 95 \%$ $\mathrm{Cl}, 1.88-3.71 ; P<.001$ ) or whose claims were denied (odds ratio $=2.53 ; 95 \% \mathrm{Cl}$, 1.61-3.97; $P<.001)$. Uninsured respondents were also less likely to be using hormones (odds ratio $=0.37 ; 95 \% \mathrm{Cl}, 0.24-0.56 ; P<.001$ ).

CONCLUSIONS Lack of insurance coverage for gender-affirming hormones is associated with lower overall odds of hormone use and higher odds of use of nonprescription hormones; such barriers may thus be linked to unmonitored and unsafe medication use, and increase the risks for adverse health outcomes. Ensuring access to hormones can decrease the economic burden transgender people face, and is an important part of harm-reduction strategies.

Ann Fam Med 2020;18:528-534. https://doi.org/10.1370/afm.2586.

\section{INTRODUCTION}

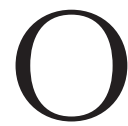
ver the last decade, transgender and nonbinary people have gained visibility, and considerable strides have been made toward addressing their health care disparities and needs. ${ }^{1-5}$ Primary care physicians play an important role in the care of this population. ${ }^{6,7}$ In addition to their routine health care needs, many transgender people seek gender-affirming or transition-related care. This care may include hormones, surgical procedures, or both. Clear guidelines support the provision of gender-affirming hormones for transgender people who seek them, ${ }^{8-11}$ and their provision is associated with improved mental health outcomes. ${ }^{12,13}$ Many of the major medical societies and associations in the United States, including the American Academy of Family Physicians, ${ }^{14}$ have issued statements in support of insurance coverage for gender-affirming care.

Despite this clear need, transgender people face a host of structural barriers to accessing care, ranging from high rates of homelessness attributable to rejection and discrimination, through lack of knowledgeable and affirming clinicians, ${ }^{15-17}$ to transphobia ${ }^{18}$ and direct discrimination in health care settings. ${ }^{19}$ In addition, many transgender people in the United States face barriers to insurance coverage for gender-affirming care. ${ }^{8}$ Transgender people often face employment discrimination leading to uninsurance. ${ }^{19}$ Those who are insured often encounter insurance policies with specific exclusions or barriers for coverage of gender-affirming therapy. ${ }^{4,20-22}$ The Patient Protection and Affordable Care Act increased coverage specifically 
for transgender people by prohibiting exclusions based on preexisting conditions ${ }^{23}$ and through the nondiscrimination clause in section 1557; however, these and other regulatory and legislative changes are in constant flux, vary by state and insurance carrier, and have not eliminated the gaps in insurance coverage for genderaffirming care. The barriers to insurance coverage combine with the other structural barriers to care to limit access to gender-affirming hormones.

These limitations may have broad implications for the health of transgender people. In the face of such barriers, 2 alternatives to the use of prescribed hormones exist. People who need hormones for gender affirmation may forgo the hormones, along with the opportunity for affirmation and improvement in their mental health and well-being. Alternatively, if unable to fill a prescription through regulated pathways, transgender people may opt to acquire their medications through other sources; this practice may expose the hormone user to a variety of risks, including toxicity from unregulated substances, incorrect use of medication, and loss of opportunity for medication monitoring and risk mitigation.

We undertook a study to assess the relationship between insurance coverage and patterns of hormone use among transgender individuals in the United States.

\section{METHODS}

Our study was approved by the institutional review board at the University of Michigan, which granted an exemption of informed consent. We used deidentified data from the US Transgender Survey, a large nonprobability sample of 27,715 transgender adults in the United States, collected online from August to September $2015 .{ }^{19}$ Respondents were aged 18 years or older, self-identified as transgender, and were recruited through a variety of venues to capture transgender respondents. Respondents were disproportionally young, White, highly educated and low income compared with the general US population. We applied survey weights based on age, race, and education from the Census Bureau's 2014 American Community Survey to help correct for this sampling bias, resulting in weights reflective of the US general population rather than the US transgender population. There is evidence to suggest that White respondents are likely overrepresented compared with the US transgender population under this weighting procedure, but bias based on age, educational attainment, or income is unclear. James et $\mathrm{al}^{19}$ provide a full description of the data collection methodology and further detail. Weighted proportions were obtained and assessments were made with weighted multivariable logistic regression analyses. We performed analyses using Stata version 15 (StataCorp LLC, Stata Statistical Software, Release 15).

Our primary outcome was use of hormones obtained from a source other than a licensed professional. The 129 respondents on active duty in military service were excluded from this question because their potential sources of care, as well as barriers to care, were unique. Another 758 respondents who identified as crossdressers were excluded from our analyses given substantial differences between this group and all other gender groups, as well as concern for inaccurate conflation. A total of 12,037 participants who were taking hormones were asked: "Where do you currently get your hormones?" Respondents who answered either "In addition to licensed professionals, I also get hormones from friends, online, or other nonlicensed sources" or "I only get hormones from friends, online, or other nonlicensed sources" were coded as using nonprescription hormones. As our outcome of interest was the use of any hormones from an unlicensed source, we combined these responses for analyses.

Our secondary outcome was defined as rate of hormone use-people who answered yes to the question, "Are you currently taking hormones for your gender identity or gender transition?"- among those who indicated that they had prior interest in taking hormones.

We identified 2 key predictors for this study: lack of insurance and insurance denial of hormone coverage. All participants were asked, "Are you currently covered by any health insurance or health coverage plan?" Respondents were coded as uninsured if they responded no. Those who reported that they were currently insured were asked whether they had been denied any, or specific, services by their insurance company over the last year. Respondents who marked yes to the statement, "My health insurance company denied me hormone therapy for transition" were coded as having coverage for hormones denied.

A number of demographic characteristics were available for use as controls in the multivariate models. Age was coded as a continuous variable. Education was categorized based on the US Census Bureau for the American Community Survey (less than high school, high school graduate, including general equivalency diploma; some college; and bachelor's degree or higher). Race/ethnicity categories were similar to those used by the US Census Bureau, with the addition of coding Middle Eastern/North African respondents as separate from White. ${ }^{14}$ Respondents were categorized as living at or near the poverty level if they had a personal income (or family income, for those sharing a household with family members) up to $124 \%$ of the federal poverty level for 2015 . The survey used a 2 -step approach to arrive at a measure 
of gender identity by asking about gender identity and sex assigned at birth. We used 5 gender categories: trans man; trans woman; people assigned male at birth who identified as genderqueer or nonbinary; people assigned female at birth who identified as genderqueer or nonbinary; and crossdresser. Analysis was additionally performed by sex assigned at birth given prior evidence for differences by this variable. ${ }^{14}$

\section{RESULTS}

A total of 27,715 people responded to the survey, of whom 26,957 identified as a gender other than crossdresser. Table 1 shows summary statistics for respondent demographics, as well as hormone use and insurance coverage. All reported values are weighted. A total of 21,237 respondents (83.43\%) were interested in using hormones and 12,037 respondents (55.04\%) were using hormones; 992 (9.17\%) of the hormone users were using nonprescription hormones.

Overall, 3,362 (15.51\%) of respondents were uninsured, compared with $12.8 \%$ of US adults at the time of the survey. ${ }^{24}$ Among insured respondents, 2,528 (20.81\%) reported that their claims were denied. The proportion of respondents indicating that they had interest in using hormones for gender affirmation did not vary by insurance status $(81.27 \%$ vs $83.83 \%$; odds ratio $[\mathrm{OR}]=1.19 ; 95 \% \mathrm{Cl}, 0.92-1.54 ; P=.19)$, but those who had insurance were more likely to be using hormones than those who lacked insurance $(57.4 \%$ vs $41.5 \%$; OR $=2.32 ; 95 \% \mathrm{CI}, 1.57-3.45 ; \mathrm{P}<.001)$.

When respondents were asked to evaluate the most pressing issues affecting transgender people in the United States, they deemed insurance coverage as one of the most important (selected by $44.11 \%$ of respondents). It ranked second only to violence against transgender people.

We conducted 4 weighted multivariate logistic regression analyses to assess the relationships between our 2 key predictors and 2 outcomes. Table 2 shows the associations between insurance status and use of nonprescription hormones and overall use of hormones. Table 3 shows the associations between insurance claim denial and use of nonprescription hormones and overall use of hormones.

Respondents who were uninsured were more likely to use nonprescription hormones than those who were insured (adjusted odds ratio $[\mathrm{aOR}]=2.64 ; 95 \% \mathrm{CI}$, 1.88-3.71; $P<.001)$. The odds of using nonprescription hormones were highest among respondents assigned male at birth (trans women and genderqueer or nonbinary individuals assigned male at birth combined compared with trans men, $\mathrm{aOR}=3.95 ; 95 \% \mathrm{CI}, 2.86-5.46$; $P<.001)$ and differed by race. Use of nonprescription hormones decreased with age $(\mathrm{aOR}=0.986 ; 95 \%$ CI, 0.975-0.996; $P=.008)$, but was not meaningfully associated with educational level or income. Among all who indicated prior interest in taking hormones, those who were uninsured were less likely to use hormones in general compared with insured counterparts $\left(\mathrm{aOR}=0.37 ; 95 \% \mathrm{CI}, 0.24-0.56_{;} P<.001\right)$.

Among insured respondents, those who reported that their insurance denied coverage of gender-affirming hormones in the past year were more likely to use nonprescription hormones than peers whose insurance covered their hormones $(\mathrm{aOR}=2.53 ; 95 \% \mathrm{CI}, 1.61-3.97$; $P<$ <001). The odds of using hormones in general among insured respondents interested in hormone use did not differ substantively between those who reported that their insurance denied coverage of gender-affirming hormones and those who had not been denied coverage $(\mathrm{aOR}=0.89 ; 95 \% \mathrm{CI}, 0.57-1.39 ; P=.60)$.

\section{Table 1. Characteristics of Respondents to the 2015 US Transgender Survey $(\mathrm{N}=26,957)$}

\begin{tabular}{|c|c|}
\hline Characteristic & Weighted Value \\
\hline Age, mean $(95 \% \mathrm{Cl}), y$ & $42.1(41.5-42.8)$ \\
\hline \multicolumn{2}{|l|}{ Gender identity, No. (\%) } \\
\hline Trans woman & $9,238(56.09)$ \\
\hline Trans man & $7,950(23.38)$ \\
\hline $\begin{array}{l}\text { Assigned female at birth, genderqueer/ } \\
\text { nonbinary }\end{array}$ & $7,844(14.03)$ \\
\hline $\begin{array}{l}\text { Assigned male at birth, genderqueer/ } \\
\text { nonbinary }\end{array}$ & $1,925(6.51)$ \\
\hline \multicolumn{2}{|l|}{ Race, No. (\%) } \\
\hline White & $21,980(64.24)$ \\
\hline Latinx/Hispanic & $1,451(15.17)$ \\
\hline Black/African American & $782(14.80)$ \\
\hline Asian/Native Hawaiian/Pacific Islander & $767(3.36)$ \\
\hline Alaska Native/American Indian & $314(0.96)$ \\
\hline Biracial/multiracial/not listed & $1,533(2.22)$ \\
\hline Middle Eastern/North African & $130(0.23)$ \\
\hline \multicolumn{2}{|l|}{ Education, No. (\%) } \\
\hline Less than high school & $892(13.85)$ \\
\hline High school & $3,384(27.55)$ \\
\hline Some college & $12,544(31.32)$ \\
\hline Bachelor's degree or higher & $10,137(27.27)$ \\
\hline At or near poverty level, No. (\%) & $8,563(29.78)$ \\
\hline Ever interested in hormones, No. (\%) & $21,237(83.43)$ \\
\hline Currently using hormones, ${ }^{a}$ No. (\%) & $12,037(55.04)$ \\
\hline Uninsured, No. (\%) & $3,362(15.51)$ \\
\hline Insurance denied hormone claim, ${ }^{b}$ No. (\%) & $2,528(20.81)$ \\
\hline Using nonprescription hormones, ${ }^{c}$ No. (\%) & $992(9.17)$ \\
\hline \multicolumn{2}{|c|}{$\begin{array}{l}\text { Notes: Because of missing values, not all categories add up to } 100 \% \text {. } \\
\text { a Of respondents who were not in active military service. This group was } \\
\text { excluded here because of their particular pathways and barriers to accessing } \\
\text { hormone. } \\
\text { b Of insured respondents who requested coverage. } \\
\text { ' Of respondents taking hormones. }\end{array}$} \\
\hline
\end{tabular}




\section{Table 2. Association Between Insurance Status and Gender-Affirming Hormone Use Among} Respondents to the 2015 US Transgender Survey

\begin{tabular}{|c|c|c|c|c|}
\hline \multirow[b]{2}{*}{ Characteristic } & \multicolumn{2}{|c|}{$\begin{array}{l}\text { Use of Nonprescription } \\
\text { Hormones, Among } \\
\text { Those Using Hormones } \\
\text { (n=12,037) }\end{array}$} & \multicolumn{2}{|c|}{$\begin{array}{l}\text { Use of Hormones, } \\
\text { Among Those Interested } \\
(n=21,237)\end{array}$} \\
\hline & aOR $(95 \% \mathrm{Cl})$ & $P$ Value & aOR $(95 \% \mathrm{Cl})$ & $P$ Value \\
\hline Uninsured (compared with insured) & $2.64(1.88-3.71)$ & $<.001$ & $0.37(0.24-0.56)$ & $<.001$ \\
\hline Age (for each additional year) & $0.986(0.975-0.996)$ & .008 & $0.969(0.96-0.98)$ & $<.001$ \\
\hline \multicolumn{5}{|l|}{ Gender identity (compared with trans man) } \\
\hline Trans woman & $3.71(2.30-5.00)$ & $<.001$ & $0.56(0.40-0.77)$ & $<.001$ \\
\hline Assigned female at birth, genderqueer/nonbinary & $2.41(1.25-4.65)$ & .009 & $0.16(0.10-0.23)$ & $<.001$ \\
\hline Assigned male at birth, genderqueer/nonbinary & $6.02(2.82-12.82)$ & $<.001$ & $0.19(0.10-0.39)$ & $<.001$ \\
\hline \multicolumn{5}{|l|}{ Race (compared with White) } \\
\hline Alaska Native/American Indian & $0.49(0.22-1.09)$ & .08 & $0.93(0.35-2.44)$ & .88 \\
\hline Asian/Native Hawaiian/Pacific Islander & $2.72(0.94-7.89)$ & .06 & $1.30(0.65-2.62)$ & .45 \\
\hline Biracial/multiracial/not listed & $3.28(1.92-5.61)$ & $<.001$ & $1.23(0.76-1.98)$ & .39 \\
\hline Black/African American & $0.92(0.55-1.56)$ & .77 & $0.75(0.40-1.38)$ & .35 \\
\hline Latinx/Hispanic & $1.07(0.60-1.89)$ & .82 & $1.01(0.51-1.97)$ & .98 \\
\hline Middle Eastern/North African & $3.68(0.66-20.45)$ & .14 & $2.06(0.50-8.39)$ & .31 \\
\hline \multicolumn{5}{|l|}{ Education (compared with less than high school) } \\
\hline High school & $1.38(0.62-3.08)$ & .43 & $0.47(0.19-1.17)$ & .10 \\
\hline Some college & $1.32(0.63-2.78)$ & .46 & $0.56(0.24-1.27)$ & .16 \\
\hline Bachelor's degree or higher & $1.13(0.51-2.50)$ & .76 & $0.50(0.22-1.15)$ & .10 \\
\hline At or near poverty level & $0.80(0.57-1.13)$ & .20 & $0.76(0.51-1.14)$ & .19 \\
\hline
\end{tabular}

Both of our outcomes were associated with gender, age, and, in some of the models, race (Tables 2 and 3). Overall use of hormones was highest among trans men and lowest among respondents assigned female at birth who identified as genderqueer or nonbinary. Respondents assigned male at birth were more likely to be using nonprescription hormones. The odds of using hormones in general-and nonprescription hormones in particular-decreased with increasing age.

\section{DISCUSSION}

This study addresses gaps in our understanding of patterns of nonprescription hormone use, as well as the relationship between insurance barriers and hormone source. Overall, we found a high rate of nonprescription hormone use- $9.17 \%$ of current hormone users, translating to approximately 75,000 people based on 2014 estimates of the US transgender population. ${ }^{25}$ Although we have no data regarding the reasons for use of nonprescription hormones, this practice enables people to bypass the clinician, thus avoiding any potential discrimination, maltreatment, or exposure, as well as the cost associated with obtaining and filling the prescription.

In this study, we found a correlation between lack of insurance coverage and use of nonprescription hormones. Additionally, we found that uninsured transgender respondents were less likely to use hormones in general.

There was substantial variation in patterns of hormone use by gender and age. Trans men were more likely to be using hormones compared with trans women, regardless of insurance status. Genderqueer or nonbinary people were least likely to be taking hormones. Trans men were less likely than all other gender categories to be taking nonprescription hormones. Older age was correlated with a decrease in overall hormone use, as well as use of nonprescription hormones; cultural shifts, along with increasing health concerns, may be at play in explaining this trend. Both the age and gender differences in hormone use patterns have clinical implications for prescription and harmreduction strategies and underscore the importance of dedicated research attention to the needs of the various subgroups in the broader transgender population. 
Table 3. Association Between Insurance Claim Denial and Gender-Affirming Hormone Use Among Insured Respondents to the 2015 US Transgender Survey

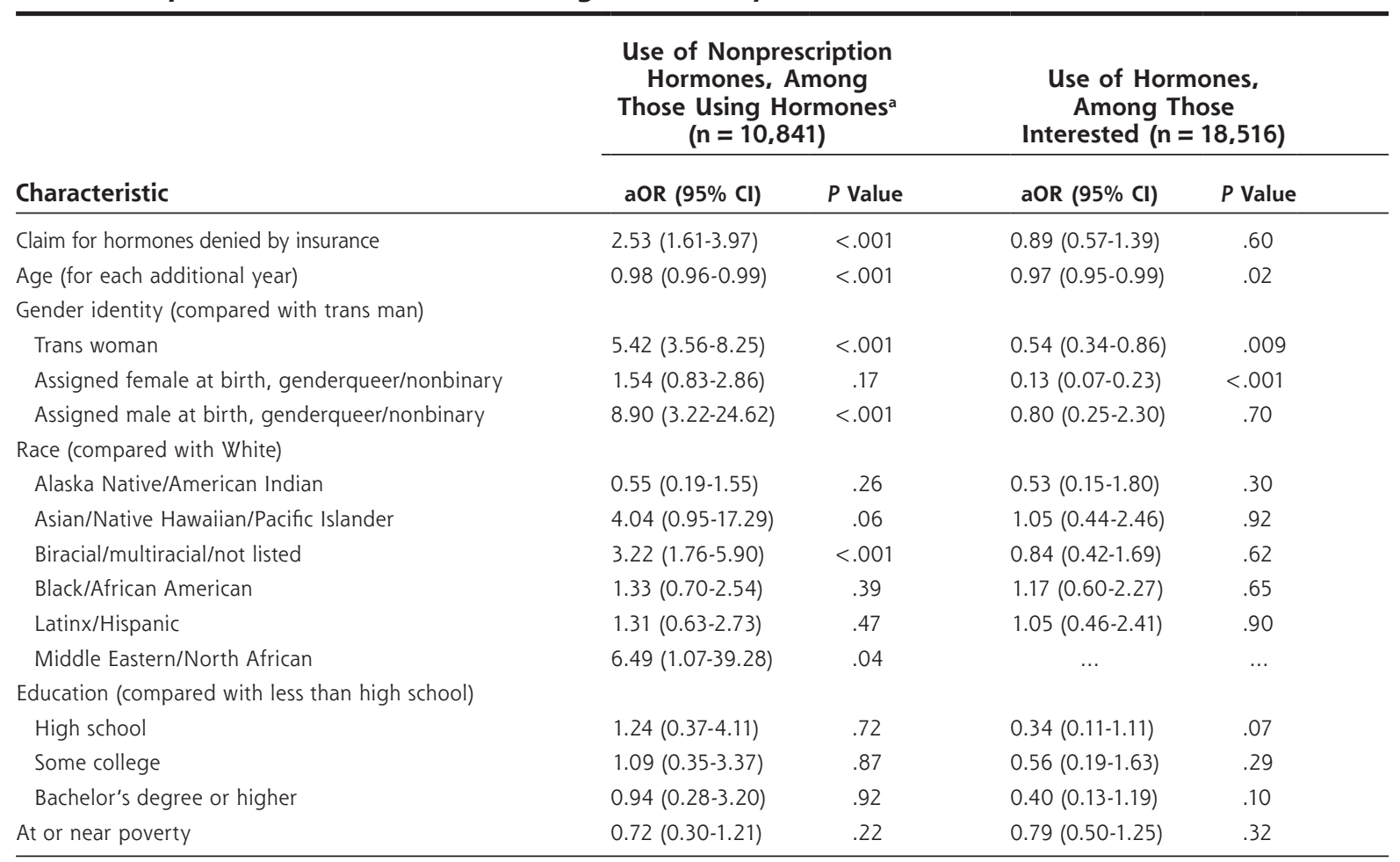

aOR = adjusted odds ratio.

Note: Data analyzed using weighted multivariable logistic regression. For all analyses, crossdressers were excluded from the overall sample because of their unique characteristics.

${ }^{a}$ Analysis excluded respondents currently in active military service, given their unique pathways to accessing gender-affirming hormones.

Respondents from some, but not all, non-White racial/ethnic groups were more likely to use nonprescription hormones. Our study may have been underpowered to detect differences between distinct groups compared with White respondents. The positive findings could be explained, however, by historical and ongoing racism and bias, and decreased trust in the health care system, that along with reduced access to health care professionals, compound other barriers to care and encourage alternative resourcing of genderaffirming hormones.

Lack of access to insurance coverage for genderaffirming hormones has implications that extend beyond economic burdens and barriers to medical transitioning. Hormones accessed from an unlicensed source may be unmonitored for content and quality, and may differ in formulation and dose from those recommended. For example, transgender women who use estrogens prescribed to cisgender women may be at increased risk for thromboembolic complications when using ethinyl estradiol ${ }^{26}$ instead of the recommended $17 \beta$-estradiol. ${ }^{10}$ Additionally, use of nonprescription hormones likely entails decreased monitoring of hormone levels and less opportunity for mitigating risks or other forms of harm reduction, preventive care, and health improvement. ${ }^{27}$

Despite these risks, use of nonprescription hormones might also be interpreted as an expression of resilience and strength among transgender people. Faced with barriers to accessing needed care, some transgender people circumvent the barriers by finding alternative resources for acquiring their medications (which have been shown to improve mental health outcomes) ${ }^{8,9}$ Future qualitative research may shed light on the reasoning and mechanisms by which transgender people navigate accessing hormones. In understanding these processes, health care clinicians can develop mechanisms for harm reduction, including institutional-level programs to ensure access to medications. Primary care physicians are ideally positioned to spearhead such efforts. As they address the practiceand clinician-level barriers to caring for transgender people, clinicians also need to be aware of the substantial cost barrier for patients without insurance or those who might have their claims denied. Insurers and policy makers should aim to eliminate these coverage gaps 
by restructuring reimbursement for gender-affirming hormones and revising exclusionary policies. Beyond the low $\cos ^{28}$ and considerable potential benefit of gender-affirming hormone coverage, there are strong ethical arguments to ensuring access to these medically necessary interventions, including the principles of beneficence, nonmaleficence, and justice. ${ }^{29}$

Our study has a number of limitations. As this is a cross-sectional study, causality cannot be inferred. The survey was a nonprobability sample and is unlikely to be completely representative of the US transgender population. Although we used survey weights to reduce sampling bias, the weighting procedure is more reflective of the US general population than the US transgender population, where those identifying as transgender are more likely to be younger and people of color. Respondents may have underreported use of nonprescription hormones because of desirability bias. Additionally, differences between types of insurance and insurance policies between states were not assessed, thereby limiting our analyses. Another limitation was the questions as posed in the survey; we do not have further detail regarding such questions as the mechanism for claim denial and we cannot quantify the proportion of medication each respondent had obtained from an unlicensed source. We also lack information regarding the specifics of insurance plans; examining out-of-pocket costs may shed further light on interactions between costs and medication use patterns, especially with the rise of high-deductible plans; however, even with access to only more general categories, we believe our findings shed light on important patterns of hormone use in this population. More research is needed to identify and evaluate interventions that reduce the risks posed by these workarounds.

The findings of this study relate to ongoing policy debates, including the debates regarding the fate of the Patient Protection and Affordable Care Act and regulatory protections of gender identity or expression. In the meantime, it is clear that greater, not lesser, protections of transgender people and their access to care are needed.

\section{To read or post commentaries in response to this article, see it online at https://www.AnnFamMed.org/content/18/6/528.}

Submitted November 20, 2019; submitted, revised, April 14, 2020; accepted May 11, 2020.

Key words: transgender; insurance; LGBT; gender-affirming hormones; risk reduction; vulnerable populations; health services

Acknowledgments: Survey data for the study were provided by the National Center for Transgender Equality.

Prior presentation: Some of these findings have previously been presented as posters at the American College of Obstetrics and Gynecology Annual Meeting, Nashville, TN, May 3-6, 2019, and the AcademyHealth Annual Research Meeting, Washington, DC, June 2-4, 2019.

\section{References}

1. Stall R, Matthews DD, Friedman MR, et al. The continuing development of health disparities research on lesbian, gay, bisexual, and transgender individuals. Am J Public Health. 2016;106(5):787-789.

2. Wanta JW, Unger CA. Review of the transgender literature: where do we go from here? Transgend Health. 2017;2(1):119-128.

3. Human Rights Campaign. HRC Releases Healthcare Equality Index, Honors Record 626 Health Care Facilities for LGBTQ Inclusion. https://www.hrc.org/press/hrc-releases-healthcare-equality-indexhonors-record-626-health-care-facili/. Accessed Dec 27, 2018.

4. Committee on Health Care for Underserved Women. Committee Opinion No. 512: health care for transgender individuals. Obstet Gynecol. 2011;118(6):1454-1458.

5. Committee on Adolescent Health Care. Committee Opinion No. 685: care for transgender adolescents. Obstet Gynecol. 2017;129(1): e11-e16.

6. Unger CA. Care of the transgender patient: the role of the gynecologist. Am J Obstet Gynecol. 2014;210(1):16-26.

7. Stroumsa D, Wu JP. Welcoming transgender and nonbinary patients: expanding the language of "women's health." Am J Obstet Gynecol. 2018;219(6):585.e1-585.e5.

8. Stroumsa D. The state of transgender health care: policy, law, and medical frameworks. Am J Public Health. 2014;104(3):e31-e38.

9. American Psychological Association. Guidelines for psychological practice with transgender and gender nonconforming people. Am Psychol. 2015;70(9):832-864.

10. Hembree WC, Cohen-Kettenis PT, Gooren L, et al. Endocrine treatment of gender-dysphoric/gender-incongruent persons: an Endocrine Society Clinical Practice Guideline. J Clin Endocrinol Metab. 2017;102(11):3869-3903.

11. World Professional Association for Transgender Health. Standards of care for the health of transsexual, transgender, and gender nonconforming people. Version 7. https://www.wpath.org/publications/soc. Accessed Dec 26, 2018.

12. Cai X, Hughto JMW, Reisner SL, Pachankis JE, Levy BR. Benefit of gender-affirming medical treatment for transgender elders: later-life alignment of mind and body. LGBT Health. 2019;6(1):34-39.

13. White Hughto JM, Reisner SL. A systematic review of the effects of hormone therapy on psychological functioning and quality of life in transgender individuals. Transgend Health. 2016;1(1):21-31.

14. American Academy of Family Physicians. Resolution No. 1004. Transgender care. https://www.aafp.org/dam/AAFP/documents/ about_us/special_constituencies/2012RCAR_Advocacy.pdf. Accessed Mar 17, 2020.

15. Jaffee KD, Shires DA, Stroumsa D. Discrimination and delayed health care among transgender women and men: implications for improving medical education and health care delivery. Med Care. 2016;54(11):1010-1016.

16. Shires DA, Stroumsa D, Jaffee KD, Woodford MR. Primary care clinicians' willingness to care for transgender patients. Ann Fam Med. 2018;16(6):555-558.

17. Stroumsa D, Roberts EFS, Kinnear H, Harris LH. The power and limits of classification - a 32-year-old man with abdominal pain. $N$ Engl J Med. 2019;380(20):1885-1888.

18. Stroumsa D, Shires DA, Richardson CR, Jaffee KD, Woodford MR. Transphobia rather than education predicts provider knowledge of transgender health care. Med Educ. 2019;53(4):398-407.

19. James SE, Herman JL, Rankin S, Keisling M, Mottet L, Anafi M. The Report of the 2015 U.S. Transgender Survey. Washington, DC: The National Center for Transgender Equality; 2016.

20. Learmonth C, Viloria R, Lambert C, Goldhammer H, Keuroghlian AS. Barriers to insurance coverage for transgender patients. Am J Obstet Gynecol. 2018;219(3):272.e1-272.e4. 
21. Cavanaugh T, Hopwood R, Lambert C. Informed consent in the medical care of transgender and gender-nonconforming patients. AMA J Ethics. 2016;18(11):1147-1155.

22. Murphy TF. Should mental health screening and psychotherapy be required prior to body modification for gender expression? AMA J Ethics. 2016;18(11):1079-1085.

23. Baker KE. The future of transgender coverage. N Engl J Med. 2017; 376(19):1801-1804.

24. Cohen RA, Martinez ME, Zammitti EP. Health insurance coverage: early release of estimates from the National Health Interview Survey, 2015. National Center for Health Statistics. https://www.cdc. gov/nchs/data/nhis/earlyrelease/insur201605.pdf. Accessed Oct 25, 2020.

25. Flores AR, Herman JL, Gates GJ, Brown TNT. How Many Adults Identify as Transgender in the United States? Los Angeles, CA: The Williams Institute; 2016.
26. Vinogradova Y, Coupland C, Hippisley-Cox J. Use of hormone replacement therapy and risk of venous thromboembolism: nested case-control studies using the QResearch and CPRD databases. BMJ. 2019;364:k4810.

27. Mepham N, Bouman WP, Arcelus J, Hayter M, Wylie KR. People with gender dysphoria who self-prescribe cross-sex hormones: prevalence, sources, and side effects knowledge. J Sex Med. 2014; 11(12):2995-3001.

28. Padula WV, Heru S, Campbell JD. Societal Implications of health insurance coverage for medically necessary services in the U.S. transgender population: a cost-effectiveness analysis. J Gen Intern Med. 2016;31(4):394-401.

29. Kuzon WM Jr, Sluiter E, Gast KM. Exclusion of medically necessary gender-affirming surgery for America's armed services veterans. AMA J Ethics. 2018;20(4):403-413.

\section{Get the Annals of FAMily Mebicine}

Editorials । Original Research । Research Briefs । Systematic Reviews । Reflections I Innovations । Departments

\section{Editorial Fellowship: Now accepting applications}

The full text of the journal is available online at hitto://www. annfammed.org and through various aggregators, including PubMed Central, EBSCO, and MDConsult. The Annals is indexed in the MEDLINE, Science Citation Index Expanded, Current Contents/Clinical Medicine, EMBASE, and CINHAL databases.

\section{EDITORIALS}

In This lssue: Nothing Simple Kurt C. Stange

The Long Loneliness of Primary Carey Timothy P. Daaleman

Clinical Prediction Rules: Challenges, Barriers, and Promises Emma Wallace; Michael E. Johansen

\section{ORIGINAL RESEARCH}

Social lsolation and Patient Experience in Older Adults

Takuya Aoki; Yosuke Yamamoto; Tatsuyoshi Ikenoue; Yuka Urushibara-Miyachi; Morito Kise; Yasuki Fujinuma; Shunichi Fukuhara

Social isolation is associated with a negative patient experience in older primary care patients in Japan. 